\title{
Marios Loukas, R. Shane Tubbs Peter Abrahams, Stephen Carmichael, Thomas Gest: Gray's Anatomy review 3rd edition
}

\author{
Academic Press, Elsevier Inc, 2022, ISBN: 978-0-323-63,916-3, 544 pp
}

\author{
Grégoire Prum ${ }^{1}[$
}

Received: 2 July 2021 / Accepted: 5 July 2021 / Published online: 20 July 2021

(c) The Author(s), under exclusive licence to Springer-Verlag France SAS, part of Springer Nature 2021

Gray's Anatomy Review 3rd edition completes now the series that began in 2010 and developed in 2016. The neuroanatomy has been included.

The authors are well known Professors of Anatomy and Clinical Anatomy: M Loukas (St. Georges's University School of Medicine, Grenada, West Indies), RS Tubbs (Tulane University School of Medicine, New Orleans, USA), PH Abrahams (Warwick Medical School, UK), S Carmichael (Mayo Clinic, Rochester, Minnesota, USA), and T Gest (University of Houston, College of Medicine, Texas, USA).

This book contains more than 1400 multiple-choice single-best-answer questions covering all of human anatomy, divided into 9 sections. These 9 sections are those of the Gray's Anatomy for Student ed 4, accompanied by an embryology section.
1. Back
2. Thorax
3. Abdomen
4. Pelvis/perineum
5. Lower limb
6. Upper limb
7. Head and neck
8. Neuroanatomy
9. Embryology

Each question has a clinical context that allows direct application of knowledge in daily practice. At the end of the chapter, the student will find the commented corrections, possibly completed by an iconography, mostly from the GAS. For each question, the authors refer to recent editions of textbooks and atlases: Gray's Anatomy for Student ed 4, Netter Atlas for Human Anatomy ed 7, Abraham's and McMinn's Clinical Atlas of Human Anatomy ed 8, and Before we are born: Essential of embryology and birth defects ed 9. The constant clinical relevance will help the memorization of the anatomical features.

These questions will be useful for the student for preparing examinations, testing his knowledge and applying the anatomical basis in a clinical situation. This "bank of questions" can also be used by the teacher to emphasize the essential data during a lecture. The single-best format is adapted to the preparation for the United States Medical Licensing Examination (USMLE) Step 1, and for the examinations at the same level in the other countries. At the end of the book, an index allows to refer directly to the region of interest.

This book is not intended to teach anatomy but to provide an excellent tool for self-assessment of knowledge and regular training. An eBook version allows an access to interactive quizzes.

Publisher's Note Springer Nature remains neutral with regard to jurisdictional claims in published maps and institutional affiliations.
Grégoire Prum

gregoire.prum@chu-rouen.fr

1 Laboratory of Anatomy, Faculty of Medicine, RouenNormandy University, 22 Boulevard Gambetta, 76183 Rouen, France 